\title{
La huella de Laforgue en el primer Eliot. ¿Un caso de práctica intertextual?
}

\section{Jorge ALCÁZAR}

Universidad Nacional Autónoma de México

A fines de 1908, siendo aún estudiante universitario, el joven T. S. Eliot descubrió un ejemplar de The Symbolist Movement in Literature en la pequeña biblioteca del Harvard Union. ${ }^{1}$ La lectura del breve libro de Arthur Symons le abriría nuevas posibilidades de expresión poética y en 1920 lo recordaría como una revelación: "an introduction to wholly new feelings". ${ }^{2}$ De los artículos reunidos en ese volumen, le llamó en especial la atención el dedicado a Jules Laforgue (1860. 1887), de tal suerte que:

I went to a foreign bookshop somewhere in Boston (I've forgotten the name and I don't know whether it still exists) which specialized in French and German and other foreign books and found Laforgue, and other poets. I can't imagine why that bookshop should have had a few poets like Laforgue in stock. ${ }^{3}$

Hacia el final de su vida, diría de Laforgue que es el escritor "al que debo más que a ningún otro poeta en cualquier idioma". 4 Siendo más explícito, en otra ocasión apuntaría que Laforgue le enseñó a expresarse: "me enseñó las posibilidades poéticas de mi propia manera de hablar". ${ }^{5}$ En este mismo escrito, Eliot detalla la naturaleza

1 Entrevista con Donald Hall de Paris Review, en Kay Dick, comp., Writers at Work. Harmondsworth, Penguin, 1972, pp. 115-116.

2 "The Perfect Critic" [1920], en Frank KeRmode, comp., Selected Prose of T.S. Eliot. London, Faber, 1975, p. 52.

3 Writers at Work, p. 116.

4 "Criticar al crítico" [1961], en Criticar al crítico y otros escritos, trad. Manuel Rivas Carral. Madrid, Alianza Editorial, 1967, p. 24. 
de la deuda contraída con algunos de los poetas franceses del siglo XIX:

Creo que de Baudelaire aprendí por vez primera un precedente de las posibilidades poéticas -jamás aprovechadas por ninguno de los poetas que escribían en mi idioma- de los aspectos más sórdidos de la metrópoli moderna, de la posibilidad de fusión entre lo sórdidamente real y lo fantasmagórico, la posibilidad de yuxtaponer lo vulgar y lo fantástico. De él, y también de Laforgue, aprendí que el género de materiales de que disponía yo, el género de experiencia con que contaba un adolescente en una ciudad industrial de Norteamérica, podían ser tema de poesía; y que el hontanar de la nueva poesía podía encontrarse en lo que hasta entonces se había considerado como imposible, estéril e irremediablemente antipoético. 6

En el estudio biográfico más documentado con que contamos, Lyndall Gordon muestra que hay un cambio sustancial en la poesía posterior a la lectura de Laforgue, es decir en los poemas producidos a partir del otoño de 1909. Hasta ese momento la vida de Eliot se había caracterizado por cierto aislamiento, y a esto contribuyeron -según señala Gordon- varios factores: el trasfondo familiar puritano, el gélido ambiente social de Cambridge, Massachusetts, su propia timidez, una actitud de desconfianza hacia las mujeres, y una suerte de atracción por observar las partes sórdidas y desagradables de Boston, que culminó en una experiencia casi mística, en la que experimentó una fugaz sensación de lo intemporal cuando las ruidosas calles de la ciudad parecieron encogerse por un momento. 7

Para una personalidad tímida como la de Eliot, con su raquítica dosis de vivencias, la actitud teatral, irónica y ambivalente que encontró en los versos de Laforgue seguramente le ofreció amplias posibilidades para enmascarar sus propios sentimientos. Como apunta Gordon:

From Laforgue, Eliot learnt to broadcast secrets, to confess through the defeatist persona his own despair and, at the same time, to shield himself by playing voices against one another - the wry voice of

6 Ibid., p. 167.

7 Lyndall GoRDON, Eliot's Early Years. Oxford, O. U. P., 1978, pp. 15-36. 
the sufferer, the scathing or flippant voice of a commentator, the banal voice of a woman. 8

Tal vez ahora la teoría impersonal de la poesía -propuesta en esa suerte de metatexto vanguardista, "Tradition and the Individual Talent" (1919) - cobre una dimensión personal y autobiográfica. Seguin decía Eliot en este ensayo: "The progress of an artist is a continual self-sacrifice, a continual extinction of personality". $Y$ añadía más adclante: "Poetry is not a turning loose of emotion, but an escape from emotion; it is not the expression of personality, but an escape from personality. But, of course, only those who have personality and emotions know what it means to want to escape from these things". 9 Pero dejemos a un lado la especulación sobre la vida y las cosas del poeta para pasar al terreno - más redituable y menos inasible-de los hechos literarios.

La influencia de Laforgue no pasó inadvertida para los coetáneos de Eliot. Ezra Pound -su amigo y colaborador-, al reseñar su primer poemario, Prufrock and Other Observations (1917), traería a colación el nombre del autor francés en un par de ocasiones. Encontraba semejanza entre la "forma regular" de "Conversation Galante" y la "modern neatness" de Laforgue. ${ }^{10}$ En efecto, como han indicado varios estudiosos, el poema de Fliot -con su tono mecánico y sus dos personajes-marioneta que se prodigan comentarios absurdos e incomunicativos- es una imitación de "Autre complainte de Lord Pierrot". Es más, Eliot termina el poema con una transcripción directa del último verso: And - Are we then so serious?' ("C'était donc serieux?") Eliot conocía el texto de Laforgue desde que leyó el ensayo de Symons, donde se le cita íntegramente.

Otro crítico que reparó en las raíces francesas de Eliot fue Edmund Wilson. En su libro todavía admirable, Axel's Castle (1931), Wilson planteaba que la poesía de Eliot descendía del simbolismo francés, mas no de la vertiente estetizante -rica en sutilezas y sugerenciascomandada por Mallarmé, sino de la línea irónico-conversacional inaugurada por Corbière y Laforgue, con su tono mixto y escurridizo que combina a la vez lo grandilocuente con lo coloquial, lo intenso

7 Lyndall GoRdon, Eliot's Early Years. Oxford, O. U. P., 1978, pp. 15-36.

8 Ibid., p. 29.

9 Selected Prose, pp. 40. 43.

10 "T. S. Eliot" [1917], en T. S. ELIOT, comp., Literary Essays of Ezra Pound. New York, New Directions, 1954, p. 420. 
con lo ingenuo. 11 Wilson cree que textos como "Prufrock" y "Portrait of a Lady" deben mucho a los poemas más extensos de Laforgue, y argüye que Eliot, en el final de "Prufrock", trata de reproducir el esquema métrico irregular de una de las primeras versiones de "Légende".12

Este es un punto interesante. A Laforgue, al igual que Gustave Kahn, se le conoce también como uno de los introductores del verso libre en lengua francesa. En la entrevista concedida al Paris Review, Eliot afirma que sus primeros ensayos con el verso libre estaban modelados en Laforgue:

My early vers libre, of course, was started under the endeavour to practise the same form as Laforgue. This meant merely rhyming lines of irregular length, with the rhymes coming in irregular places. It wasn't quite so libre as much as vers. ${ }^{13}$

No debemos olvidar que el grado de libertad que pretendía alcanzar Eliot era relativo. En un polémico artículo de 1917, presentaba al vers libre como una especie de mito formal moderno: "this preposterous fiction", y veía la práctica de los poetas que lo explotaban como confusa y contradictoria.

Vers libre has not even the excuse of a polemic; it is a battle-cry of freedom, and there is no freedom in art. And as the so-called vers libre which is good is anything but 'free', it can better be defended under some other label. [...] If vers libre is a genuine verse-form it will have a positive definition. And I can define it only in negatives: (1) absence of pattern, (2) absence of rhyme, (3) absence of metre. ${ }^{14}$

Sin embargo, para él los elementos de recurrencia, rima y el uso de metro eran necesarios, dignos de aprovecharse y tal vez no descartables por completo; según apunta más adelante: "the ghost of some simple metre should lurk behind the arras in even the 'freest' verse". Sus comentarios finales parecen distanciarse de toda moda pasajera que pretenda innovar por el sólo hecho de hacerlo.

11 Axel's Castle. New York, Scribners, 1931, pp. 93-96.

12 Ibid., pp. 96-98.

13 Writers at Work, p. 120.

14 "Reflections on Vers Libre" [1917], en Selected Prose, p. 32. 
And as for vers libre, we conclude that it is not defined by absence of pattern or absence of rhyme, for other verse is without these; that it is not defined by non-existence of metre, since even the worst verse can be scanned; and we conclude that the division between Conservative Verse and vers libre does not exist, for there is only good verse, bad verse, and chaos. ${ }^{15}$

Seguramente habría utilizado el último apelativo para designar la poesía de Whitman o Lawrence, quienes realmente se liberaron de cualquier restricción métrica.

El aprovechamiento intertextual de Laforgue abarca desde el préstamo y la reescritura de versos aislados, como en "Conversation Galante", hasta el sesgo estratégico que le da Eliot a la presentación de la conciencia o la voz del poema. Otros casos del primer tipo los encontramos en "La Figlia Che Piange", cuya línea "Simple and faithless as a smile and shake of the hand" está tomada de "Pétition": "Simple et sans foi comme un bonjour"; 16 y en "Rhapsody on a Windy Night" cuyos versos, "Regard the moon,/ La lune ne garde aucune rancune", parecen provenir de "Complainte de cette bonne lune":

Là, voyons, mam'sell' la Lune,

Ne gardons pas ainsi rancune;

En relación con este mismo poema, Michael Hamburger ha sugerido ${ }^{17}$ que el pasaje de "The Hollow Men"

Here we go round the prickly pear

Prickly pear prickly pear

Here we go round the prickly pear

At five o'clock in the morning.

con su tono de ronda infantil, tal vez esté inspirado en los últimos versos de la queja lunar laforguiana:

Sous l' plafond

Sans fond,

On y danse, on y danse

Sous l'plafond

15 Ibid., p. 36.

16 Michael Hamburcer, The Truth of Poetry. Harmondsworth, Penguin, 1972, p. 59.

17 Ibid., p. 36. 
Sans fond,

On y danse rous en rond.

Más que apropiarse de textos enteros, Eliot -en concordancia con una práctica vanguardista harto extendida- parece interesarse por detalles alusivos, estrategias de presentación, tono y atmósfera. En algunos casos pareciera que el poeta inglés ha dado con un elemento o una expresión nimia que él explota más ampliamente en sus propios poemas. Comparemos el inicio de dos textos.

Paris chahute au gaz. L'horloge comme un glas

Sonne une heure. Chantez! dansez! la vie est brève,

Tout est vain, —et, là-haut, voyez, la Lune rêve

Aussi froide qu'aux temps où l'Homme nétait pas.

("Soir de carnaval")

Twelve o'clock.

Along the reaches of the street

Held in lunar synthesis,

Whispering lunar incantations

Dissolve the floors of memory

("Rhapsody on a Windy Night")

En ambos pasajes hay tres elementos comunes: la indicación de la hora, el ambiente nocturno y la referencia lunar que sugiere una regresión temporal hacia un momento primigenio. En el poema de Laforgue, estos elementos no vuclven a aparecer; su desarrollo fluye en otra dirección: se transforma en una reflexión sobre la vanidad terrena ("où sont les cendres du Psalmiste?") y pasa a ser una suerte de advertencia sobre nuestra inminente mortandad: "Et moi, combien de jours me reste-t-il à vivre?" En el texto de Eliot los tres elementos se tematizan. Al principio de casi todas las divisiones estróficas se indica la hora ("Half-past one" [...] "Four o'clock"). El poema es una exploración onírico-surrealista de los aspectos sórdidos del mundo nocturno. La luna cobra la vidla propia de la prosopopeya y los versos se caracterizan por la extrañeza impactante de sus imágenes: "Midnight shakes the memory/As a madman shakes a dead geranium". La luz citadina, mencionada tan someramente en el texto de Laforgue, también aparece en el de Eliot: "Every street lamp that I pass/Beats like a fatalistic drum"; pero, además de personificársele, cobra mayor importancia: sirve como una especie de guía oracular del itinerario que se nos presenta. 
Half-past three,

The lamp sputtered,

The lamp muttered in the dark.

The lamp hummed:

'Regard the moon,

La lune ne garde aucune rancune,

She winks a feeble eye,

She smiles into corners.

She smooths the hair of the grass.

The moon has lost her memory.

A washed-out smallpox cracks her face,

Her hand twists a paper rose,

That smells of dust and eau de Cologne,

She is alone

With all the nocturnal smells

Than cross and cross across her brain.

En varios poemas de Laforgue es común encontrar a un noctámbulo o a un insomne que no se identifica con su entorno urbano.

Sous le gas cru j'allais à l'heure où l'enfant dort.

Des spectres maquillés traînaient leur jupon sale,

Les cafés se vidaient, un bal, par intervalle,

M'envoyait un poignant et sautillant accord.

("Stupeur")

Al igual que Eliot, Laforgue define la atmósfera de sus poemas por medio de detalles sinecdóticos, ya sean éstos sonoros ("un poignant et sautillant accord") o visuales ("jupon sale"). Vale la pena cotejar el segundo verso del texto citado con este trozo de "Rhapsody":

The street-lamp said, 'Regard that woman

Who hesitates toward you in the light of the door

Which opens on her like a grin.

You see the border of ther dress

Is torn and stained with sand,

En ambos casos, el estado de la vestimenta parece indicar simbólicamente la naturaleza espiritual de sus respectivos portadores.

Por lo que toca al aspecto sonoro, en los textos de Laforgue abundan las referencias musicales. A veces las utiliza para evocar el ambiente que rodea a un lugar: 
Hier l'orchestre attaqua

Sa dernière polka, Hier, la dernière fanfare

Sanglotait vers les gares

("Légende")

En otras las usa para vehicular el estado de ánimo que circunda lo descrito:

Les cors, les cors, les cors! ...

S'en sont allés au vent du Nord.

("L'hiver qui vient")

$\mathrm{Oh}$ ! les après-midi solitaires d'automne!

Il neige à tout jamais. On tousse. On n'a personne.

Un piano voisin joue un air monotone;

Et, songeant au passé béni, triste, on tisonne.

("Les après-midi d'automne")

Todo esto recuerda un poco varias de las imágenes de "Portrait of a Lady": "the ariettes/Of cracked cornets"; "Capricious monotone"; "The voice returns like the insistent out-of-tune/Of a broken violin on an August afternoon". Sin embargo, de nuevo en Laforgue no encontramos la recurrencia isotópica que encadena los detalles y los hace formar parte de un entramado orgánico -como en el poema de Eliot - que dramatiza el apuro emotivo de la persona textual:

\author{
I keep my countenance, \\ I remain self-possessed \\ Except when a street-piano, mechanical and tired \\ Reiterates some worn-out common song
}

En el artículo de Pound, al que tuvimos oportunidad de referirnos antes, encontramos este comentario sobre Eliot: "It would be possible to point out his method of conveying a whole situation and half a character by three words of a quoted phrase". 18 En efecto, son famosos los paréntesis de "The Love Song of O. Alfred Prufrock" que incorporan otra voz diferente de la del protagonista que enuncia el poema:

18 Literary Essays of Ezra Pound, p. 419. 
(They will say: 'But how his arms and legs are thin!')

Este rasgo tampoco está ausente en Laforgue. En "Légende", un poema citado antes, encontramos este tipo de comentario parentético, intercalado en una conversación imaginaria entre el yo poético y una mujer:

(Oh! comme elle est maigrie!

Que va-t-elle devenir?

Durcissez, durcissez,

Vous, caillots de souvenir!)

En el poema de Eliot, por medio del paréntesis se nos da otra faceta de Prufrock, como se le podría ver desde el exterior, observado desde otro ángulo; mientras que en el caso de Laforgue, la voz masculina nos presenta, de manera irónica, al hipotético objeto amado como lo ve la entidad que lo desea y que posteriormente renuncia a él, por no ser más que el tema de leyendas propias de la infancia.

Entre las posibilidades poéticas que Eliot asimiló de Laforgue se encuentran las modalidades enunciativas con que puede manejarse el monólogo dramático: el entretejido de voces dispares $y$, como ha reparado Stephen Spender, la doble focalización con que se puede presentar al protagonista:

Laforgue wrote dramatic monologues in which the narrator, though speaking in the first person, was viewed objectively and ironically as though by an outsider. There was an elaborate disguise, a mask, which was the form of this inner dramatic monologue or soliloquy written in the first person, but in which the poetry seemed to have a separate consciousness projected, which looks ironically at this first person ' $I$ ' as a third person 'he'.19

La mayoría de los poemas recogidos en el libro póstumo Derniers z'ers (1890) son de este tipo. De la docena de textos que lo componen, destacan "L'hiver qui vient", "Légende" y "Solo de lune". Los "héroes" de Laforgue, al igual que los del primer Eliot, gustan de especular sobre pasos no dados o deseos olvidados, sobre pasados o inventados

19 Stcphen SPENDER, Eliot. London, Fontana/Collins, 1975, p. 27. 
amores que nunca fructificaron. Por ejemplo, "Solo de lune" es el monólogo de un hombre que viaja recostado sobre el techo de una diligencia. Sus palabras entrelazan el avance del vehículo con los recuerdos de una mujer, los lugares que pasan y la presencia de la luna:

La Lune se lève,

$O$ route en grand rêve! ...

On a dépassé les filatures, les scieries,

Plus que les bornes kilométriques,

En el poema resaltan memoria, especulación y movimiento, así como la reiteración punzante de un romance fallido:

Nous nous aimions comme deux fous,

On s'est quité sans en parler,

Un spleen me tenait exilé,

Et ce spleen me venait de tout. Bon.

Ses yeux disaient: "Comprenez-vous?

Pourquoi ne comprenez-vous pas?"

Mais nul n'a voulu faire le premier pas,

Voulant trop tomber ensemble à genoux.

(Comprenez-vous?)

En el texto se conjuntan un detalle sinecdótico de la mujer (su mirada) y lo que ésta parece insinuar. Este es un elemento iterativo que aparece de nuevo:

Ses yeux clignaient: "Comprenez-vous?

Pourquoi ne comprenez-vous pas?"

En "Prufrock" encontramos un procedimiento semejante, que también se reitera un par de veces, pero con sentido inverso: Prufrock especula sobre una presunta insinuación inferida, que la mujer en cuestión negaría como tal:

If one, settling a pillow by her head,

Should say: 'That is not what I meant at all.

That is not it, at all'. 
El protagonista del poema de Laforgue termina su discurso de amor conjetural con una nota de trivialidad disonante: el fresco de la noche lo lleva a pensar en qué hará ella en ese momento y la imagina caminando, "(Elle aime tant errer tard!)", y en peligro de pescar un resfriado, "Oh soigne-toi, je t'en conjure!" Finalmente regresa a la aflicción iterativa que define al poema:

Ah! que ne suis-je tombé à tes genoux!

Ah! que n'as-tu défailli à mes genoux!

J'eusse été le modèle des èpoux!

Comme le frou-frou de ta robe est le modèle des frou-frou.

Vale la pena detenerse en este final muy de Laforgue. En primer lugar cabe destacar la rima que ironiza la situación del narrador. Este empleo de la rima es muy parecido a lo que hace Eliot en "Prufrock":

Is it perfume from a dress

That makes me so digress?

[...]

Should I, after tea and cakes and ices,

Have the strength to force the moment to its crisis?

Por otra parte, la textura táctil-sonoro-sensorial del último verso recuerda otra línea de "Prufrock":

$[\ldots]$ after the skirts that trail along the floor

Por último, el uso del subjuntivo para cavilar sobre algo que nunca sucedió. En "Prufrock" encontramos una modalidad verbal equivalente en dos largas secciones que comienzan igual: "And would it have been worth it, after all." Como dice el propio Eliot sentenciosamente en otra parte:

What might have been is an abstraction

Remaining a perpetual possibility

Only in a world of speculation.

$$
\text { ("Burnt Norton", I) }
$$

Hay varios rasgos, como los que hemos señalado, dispersos en diversos textos de Laforgue —en algunos casos totalmente disímbolos 
de los de Eliot-- que, de alguna manera, parecen haber migrado hacia "Prufrock". Por ejemplo, en "Fantaisie" leemos:

Mais il est temps encor! Ah! trouvons quelque chose.

En el poema de Eliot, la posible plenitud del tiempo futuro se tematiza:

And indeed there will be time

[...]

There will be time to murder and create,

And time for all the works and days of hands

En otras ocasiones, nos topamos con una constelación de detalles, provenientes de distintas partes, que se aglutinan en un segmento de texto. En un pasaje de Laforgue se maneja el elemento isotópico submarino:

La vie éclôt au fond des mers des premiers âges, Monades, vibrions, polypiers, coquillages.

("Litanies de misère")

Esto sugiere el ambiente marino y limitadamente desarrollado que circunda el momento climático de "Prufrock":

I should have been a pair of ragged claws

Scuttling across the floors of silent seas.

Sin embargo, este aspecto de la conciencia racional que reniega de su bagaje cultural en favor de una constitución más afin con las pulsiones elementales de la vida, lo podemos ubicar más explícitamente en los últimos versos de "Étonnement":

$$
\begin{aligned}
& \text { J'irai vivre, là-bas, seul, dans quelque forêt } \\
& \text { D'Afrique, brute épaisse, et la chair assouvie, } \\
& \text { J'oublierai le cerveau que les siècles m'ont fait. }
\end{aligned}
$$

De la producción primera de Laforgue $-y$ aun a pesar de su brevedad - el poema que tal vez guarde más afinidad con "Prufrock" sea "Pour le livre d'amour". Al igual que "The Love Song", desde el mismo título nos podemos percatar del tratamiento irónico del tema. Y mientras que Eliot maneja la penuria afectiva de su protagonista de manera sugerente, Laforgue la hace transparente. 
Je puis mourir demain et je n'ai pas aimé.

Mes lèvres n'ont jamais touché lèvres de femme,

Nulle ne m'a donné dans un regard son âme,

Nulle ne in'a tenu contre son cour pâmé.

En ambos casos se nos presentan seres ambivalentes y contradictorios que alojan por igual el deseo y el recato, y que además, se desenvuelven en un marco social - a la vez superficial y mundanoante el cual se muestran tímidos y apocados.

Partout, dans les salons, au théâtre, à l'église,

Devant ces hommes froids, les plus grands, les plus fins,

Et ces femmes aus yeux doux, jaloux ou hautains

Dont on redorerait chastemet l'âme exquise,

Je songeais: tous en sont venus là! J'entendais

Les râles de l'immonde accouplement des brutes!

Tant de fanges pour un accès de trois minutes!

Hommes, soyez corrects! ô femmes, minaudez!

Los últimos versos bien podrian aplicarse a "the young man carbuncular" de The Waste Land o a las peripecias eróticas de un Sweeney.

Tanto Prufrock como la voz anónima de este pocma parecen pertenecer a la especie de chivos expiatorios que creen, en un gesto de desmesurada grandilocuencia, que llevan a cuestas las culpas de la humanidad y que en su sufrimiento, y en su infructuosa búsqueda de la virtud, estriba la razón sine qua non para redimir al mundo.

Je n'ait fait que souffrir, pour toute la nature,

Pour les êtres, le vent, les fleurs, le firmament,

Souffrir par tous mes nerfs, minutieusement

Souffrir de n'avoir pas d'âme encore assez pure.

Symons decía: "It is an art of the nerves, this art of Laforgue, and it is what all art would tend towards if we followed our nerves on all their journeys." Y es evidente que Eliot siguió el consejo al pie de la letra:

It is impossible to say just what I mean!

But as if a magic lantern threw the nerves in patterns on a screen:

Finalmente, y para no perder de vista el ensayito de Symons, quisiera referirme al tono hiperbólico que contamina el discurso de Prufrock y que podríamos ejemplificar con un par de versos: "To have 
squeezed the universe into a ball/To roll it towards some overwhelming question". Ha sido un lugar común de la crítica, que ha intentado desenmarañar la alusividad de Eliot, atribuir el origen intertextual de estos versos al poema metafisico de Marvell, "To His Coy Mistress":

Let us roll all our strength, and all

Our sweetness, up into one ball

Esto parece un hecho incontrovertible. Mas quisiera aventurar otra posibilidad, que además serviría para ilustrar más ampliamente el origen constelado de los préstamos de Eliot. Si no me engaño, una de las fuentes intertextuales se encontraría en lo que dice Symons sobre Laforgue:

In Laforgue, sentiment is squeezed out of the world before one begins to play at ball with it. ${ }^{20}$

La única justificación que puedo dar a esta propuesta es citando a Eliot sobre el modo en que el poeta devora y digiere su experiencia en su condición de ente perceptivo.

When a poet's mind is perfectly equipped for its work, it is constantly amalgamating disparate experience; the ordinary man's experience is chaotic, irregular, fragmentary. The latter falls in love, or reads Spinoza, and these two experiences have nothing to do with each other, or with the noise of the typewriter or the smell of cooking; in the mind of the poet these experiences are always forming new wholes. 21

Ahora bien, para entender los mecanismos mentales del escritor debemos dar un pequeño rodeo. Eliot se manifestó desde los inicios de su carrera, como apuntamos antes, en favor de la impersonalidad de la poesía. Para él lo que importaba era el texto en sí, y no las circunstancias personales de su gestación. '(Aunque ahora sabemos por las biografias de Lyndall Gordon y Peter Ackroyd que su poesía es en buena medida autobiográfica.) En "Tradition and the Individual Talent", Eliot decía que "the poet has, not a 'personality' to express,

\footnotetext{
20 Arthur Symons, The Symbolist Movement in Literature. New York, Dutton, 1958, p. 60 .

21 "The Metaphysical Poets" [1921], en Selected Prose, p. 64.
} 
but a particular medium, which is only a medium and not a personality, in which impressions and experiences combine in peculiar and unexpected ways". 22 Eliot trató reiteradamente de alejarse de las teorías mentalístico-expresivas de los poetas románticos, en que destacaban el proceso revivificador de la memoria y la fuerza generativa de la imaginación, para darle más peso al valor de la obra en sí, a la excelencia técnica del verso.

No obstante, este intento por desentenderse de la actividad psicológica del artista resulta infructuoso, ya que la explicación que nos ofrece Eliot sobre el amalgamiento de la experiencia personal se podría ver como un esquema de sus procesos mentales. En lugares diversos de su prosa crítica, hay destellos y sugerencias de cómo actúa la mente del creador. El proceso en sí no es un acto deliberado, puesto que el escritor empolla su poema y no sabe qué saldrá del cascarón hasta que el texto está terminado (The Use of Poetry and the Use of Criticism). No sabe qué quiere decir sino hasta que encuentra las palabras necesarias ("The Three Voices of Poetry"). El acto de la creación es un modo de recuperar lo que se encuentra suspendido y en estado latente en las profundidades del poeta (The Use of Poetry). Y aquí es donde entra en juego la amalgama de estímulos dispares. Es como una especie de caleidoscopio subliminal que, dependiendo de cómo se le mueva, forma figuras distintas. Así la vivencia subjetiva puede estar al lado de la experiencia de la lectura literaria. Y en un par de versos, como los de "Prufrock", se pueden fundir las huellas verbales que dejan en la mente del poeta textos tan disímbolos como un poema de Marvell o un ensayo de Symons, o los casos de imágenes consteladas provenientes de Laforgue. Los ejemplos se pueden multiplicar, pero no viene al caso. Lo que importa y razonablemente se puede desprender de todo esto es que debemos repensar nuestras hipótesis de los fenómenos intertextuales. Ya que, como se ha sugerido en el caso de Eliot y a pesar de sus múltiples despotricamientos en contra de los románticos, nos hemos topado con un esbozo mentalista de la intertextualidad. 